\title{
The Value of Preparation in a Systems Engineering Masters Module: A Longitudinal Case Study
}

\author{
Siebert Benade ${ }^{1}$ and Ronel Callaghan ${ }^{2}$,* \\ ${ }^{1}$ Graduate School of Technology Management, University of Pretoria, Pretoria 0002, South Africa ${ }^{2}$ Science, Mathematics \\ and Technology Education, University of Pretoria, Pretoria 0002, South Africa
}

\begin{abstract}
This research emanates from a systems-oriented process of investigation into the educational approach of masters in engineering management programmes in order to find ways to improve student through-put rate and the quality of learning. The document describes the educational process, with specific emphasis on student preparedness, including the value and impact of a pivotal preparation test. This process is guided by constructive alignment; learning cycles through interactive blended teaching; and a focus on student learning. A longitudinal descriptive case study of the programmes was undertaken, focusing on a systems engineering module, which is integral to all masters programmes. The case is described with regard to its context; the educational process and teaching approach; and an educational and statistical analysis of the preparation test.

The main contribution of the paper is the resulting structured, holistic, and integrated education process, designed to address the challenges, including a specific focus on student preparation and the pivotal preparation test. A clear link was established between student preparedness and the subsequent levels of teaching and learning. The preparation test was found to be on the relevant cognitive level; a predictor of course success; influencing positively the motivation of students; as well as impacting on the adaptation of the educational process. The use of the adapted Bloom's taxonomy to evaluate cognitive levels of an intervention; the application of learning cycles and constructive alignment; as well as the impact of a preparation test, can significantly enhance the quality of the education process and consequently, student through-put rates. ๑ 2014 Wiley Periodicals, Inc. Syst Eng 00: 1-15, 2014
\end{abstract}

Key words: postgraduate engineering education; systems engineering education; learning cycles; blended learning; levels of learning

\footnotetext{
* Author to whom all correspondence should be addressed (e-mail: ronel.callaghan@up.ac.za).
}

\section{INTRODUCTION}

This paper describes a systems engineering (SE) driven investigation into the design of engineering and project management masters qualifications. The investigation explores the state of the teaching practice within these programmes, with 
the aim to identify and address specific challenges and thus to improve both the throughput rate and the quality of the qualifications. A descriptive case study, focusing on the SE module within the programmes is described. The education approach furthermore seeks to acknowledge and apply key SE principles. The total system, total life-cycle and the integration and management of diverse and often contradictory perspectives are addressed. Hence, the ability to manage multidisciplinary problems is essential. The approach results in multiple perspectives and the emergence of new approaches, views and properties [Blanchard \& Fabrycky, 2010]. The main contribution of the paper is the presentation of the resulting structured, holistic and integrated education process, designed to address the challenges, including a specific focus on student preparation, and a pivotal preparation test, within this process. To achieve this, both SE and Educational theory and experience are required and carefully integrated.

The engineering profession is of the utmost importance in the South African context in terms of the establishment and sustainability of infrastructure, the development of the economy and the alleviation of poverty. The Engineering Council of South Africa (ECSA) also recognizes that South Africa has a severe shortage of engineering professionals, and supports the development of quality engineering education [Franks, 2011]. The ECSA strategic plan (2010-2014) focuses on the "engineering skills pipeline, transformation and stronger linkages with industry."

Various factors contribute to the fact that this, however, is also a challenging teaching and learning environment [Case, 2006]. The challenges are more pronounced in post graduate Engineering studies in South Africa with added issues such as the part-time nature of courses (limited contact time), resource challenges, larger class-groups, the diversity of students (personal, social, professional, and educational) and the complex nature of the field of study. One of the main issues arising from these challenges is a low throughput rate, which places a burden on limited resources. Engineering schools are constantly revisiting their educational approach in a quest to address these challenges [Auer, Dobrovska, and Arthur, 2012] and in an attempt to produce well-qualified and competent engineering professionals.

\section{BACKGROUND}

The research originates from an ongoing investigation into the masters programmes in a postgraduate School of Technology Management at a research-intensive university in South Africa. The school presents three ECSA-accredited engineering management masters programmes, namely engineering management (MEM), technology management (MTM), and project management (MPM). Admission requirements to these programmes include a degree (a 4-year engineering degree, or a 4-year BSc/BTech honors degree) as well as a minimum of 3 years' industry experience. Each programme consists of a number of modules to be completed per semester, as well as a research project that is undertaken during the last year of study. The nature of these disciplines is such that it is advantageous for students to work full-time and study part-time. Industry is the "laboratory" in this case, not aca- demic laboratories where physical experiments are performed [Stephens, 2013]. All programmes are hence offered on a part-time, modular basis over 2 years.

The programmes seek to strike a balance between theory and application, individual and group learning activities, faceto-face (f-2-f) and distance learning, and assessment opportunities. A blended (mixed) teaching and learning model was developed over the last 14 years to accommodate students' specific circumstances. A consequence of this model is that f-2-f contact is limited (only 2.5 days per module) and needs to be carefully managed and fully utilized. Class contact is interactive, and includes lectures, tests, guest lectures, student group work, class discussions, and presentations. The postcontact period is typically concluded with group assignments and final written examinations. All modules are web-enabled through a learning management system (LMS), managing academic communication as well as distributing study material and assignments.

The paper describes the educational process, with emphasis on student preparedness within the structure of the engineering masters programmes, with specific reference to the SE module. Relevant pedagogical theories are explored. An educational and statistical analysis is furthermore done to strengthen the arguments and to determine whether or not a preparation test can be used as a predictor of and guide toward successful completion of the SE module.

Originally, SE was an elective module on all programmes. Since 2001, SE has been made compulsory. Since 2008 students can also enroll for the SE domain-a focus area within the MEM programme. This offering includes modules such as reliability engineering, engineering logistics, decision making and risk management, systems architecture and asset management, with a focus on life-cycle management and sustainability. These students will typically do their capstone research project on a SE topic. This SE domain will most probably qualify as a masters in SE as described in the Graduate Reference Curriculum for SE [Pyster et al., 2012]. The programme architecture in this case is system centric, composed of approximately $70 \%$ SE related work. All masters programmes commence with a SE module to lay the foundation of system thinking and application. The rationale of the whole programme design, which includes the other modules and their integration into the programme, are also addressed in the SE module. The SE module is therefore used as a case study for this paper.

\section{RESEARCH APPROACH}

\subsection{Problem Statement}

The underlying problem in this research is students' unacceptable throughput rate and completion time for the engineering masters programmes. Currently, an approximate figure for the throughput rate of all programmes combined is that onethird of students complete their programme in the prescribed 2 years, one-third complete their study in 3-4 years, and the remainder never complete their studies.

A range of factors could cause this problem, as suggested in the introduction. The generic challenges in teaching in the 
Engineering Sciences include the diversity of students and the complex nature of the field of study. These factors are even more pronounced in the postgraduate education and training of engineers in South Africa. Postgraduate courses are usually part-time courses and students are often in demanding fulltime positions. The students typically come from diverse educational backgrounds, are dispersed over South Africa, Africa and even further abroad, and have different levels of professional experience. Time and location issues, long distances to travel to class, unreliable internet connectivity and language and cultural barriers add to the challenges. The fact that many students do not complete their studies in the desired 2 years creates more pressure on the available resources. The current investigation into the engineering masters programmes focuses on logistical, financial, demographical, and cultural challenges, and detailed analysis of throughput rates. The focus of this paper is, however, on the teaching and learning strategy within these programmes.

SE specific challenges include the fact that the module is built on practice-based topics that are a mixture of theory, heuristics, process and so-called best practice. The notion of heuristic is defined as "pseudo-science with proven practical value" [Maier and Rechtin, 2009]. There always is the danger that SE problem-solving is approached following a recipe, without real understanding, and overdocumentation without adding any value. Some people, for example, believe that SE can only be successfully applied in military and aerospace environments, which causes a negative perception of SE in industry and business in general.

These challenges create an urgent need for well-designed and applied teaching and learning processes, and lead to the important reflective, quality assurance and review processes applied in the engineering management masters programmes. Two specific problems were identified within the teaching and learning activities of these programmes, and were the focus for investigations described in this paper:

1. Students often do not prepare adequately, which negatively influences the teaching and class interaction during the f-2-f sessions. This limits teaching strategies during f-2-f sessions mainly to lecturer-centered, rather than student-centered, strategies. This hampers the f-2-f teaching and learning of theory, heuristics, process and practice, and therefore the development of the high cognitive levels expected in the module.

2. The lecturer and the students cannot adequately identify on which cognitive level they are with regard to the module material, which implies that neither lecturers nor students can effectively adapt their work-method towards improving all other interactions, and thus also end-results.

\subsection{Research Question}

The main research question is: how can students' effective preparations, as assessed in a preparation test, positively influence teaching and learning activities in a SE module?
Two subquestions are subsequently investigated:

1. How can masters in engineering and project management programmes be structured to support student preparedness?

2. How can a preparation test be implemented to support student preparedness?

(a) How can the preparation test motivate students to prepare more effectively towards meaningful f-2-f interaction?

(b) Are the SE items in the preparation test posed at appropriate cognitive levels given the stage of learning?

(c) How can the results of the preparation test contribute to in-process adaptation of teaching and learning activities in the SE module?

(d) Can the results of the preparation test be considered as a meaningful predictor of course success?

\subsection{Research Methodology}

The research is based on a longitudinal descriptive case study of the educational processes within the SE modules of the engineering management masters programmes. Case-study research provides the opportunity to investigate and describe a bounded system while utilizing multiple sources of information [Creswel, 2013; Yin, 2013]. This research is focusing on one concern embedded within the SE case study, namely the significance and management of student preparation within the educational processes. The case is bounded by time (a period of 11 years); place (situated at the university where the specific programmes are presented); as well as size (the embedded focus within the SE modules). The longitudinal data, on which the investigation is based, was created over a period of 11 years and originates from a variety of sources.

\subsection{Data Collection and Analysis}

The engineering and project management programmes and specifically the SE module investigated in this longitudinal case study developed over a period of 11 years. This development was evaluated and documented continuously as part of the university's internal quality assurance processes, as well as for external review purposes with ECSA. This research is based on data that originates from these evaluations, and includes statistical data of test and examination results, interviews with lecturers, student feedback, observations, and reflections of the educational process, documentation about the development of the educational process, study guides and other study material, and other documentation of the review processes.

The following section describes a selection of this data as a case study, in order to contextualize the SE module. It also describes the investigation into research subquestion 1: how can the masters programmes be structured to support student preparedness? 


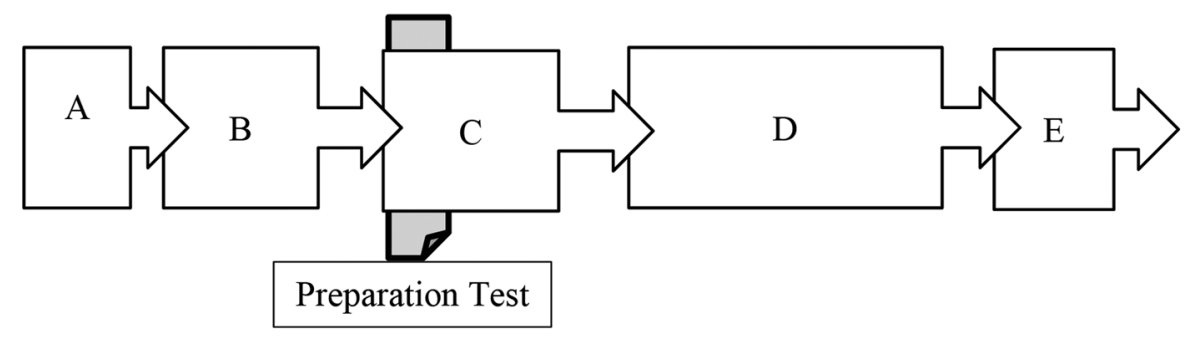

Figure 1. Engineering management masters module life cycle.

\section{THE CASE: A SE MODULE}

\subsection{Background}

The SE module is presented as a foundation for systems thinking and awareness in the engineering and project management masters programmes. SE is taught with associated theory, guiding principles, heuristics and application. The INCOSE Systems Engineering Handbook: A Guide for System Life cycle Processes and activities is the prescribed Textbook for SE modules since 2012 [INCOSE, 2011]. Previously the book: Systems Engineering Management [Blanchard, 2008], was used. The required outcomes of the SE modules were originally derived from the engineering management programme outcomes. Later, with the use of the INCOSE SE handbook as well as graduate reference curriculum for SE [Pyster et al., 2012] some outcomes and detail SE topics were adapted. The key focus areas of the SE modules are the life-cycle approach, the notion of a whole system, and the holistic or bigger picture as the point of departure of any human-made system. The SE life-cycle stages and associated processes are derived from figure 1.1 and table 3.1 in the INCOSE handbook respectively. Processes are typically repeated until risk and technical progress are at acceptable levels (also called stage-gate approach). SE concepts are applied to a variety of areas and types of systems, such as physical systems, information systems and organizational systems. Specific emphasis is placed on the different roles of the systems integrator versus manufacturer (of subsystems) as depicted in figure 3.3 in the INCOSE handbook. The learning and teaching process and associated enabling infrastructure of the engineering masters programmes can indeed also be perceived and managed as a highly interrelated system.

\subsection{Educational Process}

The educational process within the masters programmes is guided by the notion of constructive alignment and learning cycles as managed through an interactive blended teaching and learning approach. The educational process for each module-including the SE modules-is illustrated in the diagram in Figure 1, and expanded further in Table I.

The first year commences with an f-2-f introductory session (A in the figure), during which students are orientated in the engineering management masters programme and the educational approach, meet staff and fellow students, and receive study material. Students typically register for four modules per semester. This is followed by a 4 -week preparation phase (referred to from now on as the acquisition phase), which is $\mathrm{B}$ in the figure. During this phase, students work in their own time and place to prepare for the modules that are presented in the $\mathrm{f}-2-\mathrm{f}$ teaching block ( $\mathrm{C}$ in the figure). A preparation test is written at the beginning of this teaching block. The contact time per module is 2.5 days, which is the only $\mathrm{f}-2 \mathrm{-f}$ teaching time available for a module. This is followed by the main study time of 14 weeks ( $\mathrm{D}$ in the figure), during which students work in their own time and place on individual and/or group assignments, and complete tests or other work as prescribed in each module. The summative assessment of each module is typically in the format of a written examination (E) at the end of the semester. Examinations are taken in person either at the university or at other approved distance venues for students who are further than $200 \mathrm{~km}$ from the university.

This paper describes the investigation into one of the focus areas in the educational process, namely the acquisition phase (B), and specifically the value of a preparation test (the grey area) before the $\mathrm{f}-2-\mathrm{f}$ sessions $(\mathrm{C})$.

\subsection{Educational Approach}

The educational concepts applied in the teaching and learning processes for this qualification, and thus also for the SE modules, are the notions of constructively aligned learning cycles as managed in a blended teaching and learning environment through interactive teaching strategies.

Constructive alignment proposes the conscious planning of teaching and learning to ensure that students can construct their own meaning through structured teaching and learning processes [Biggs and Tang, 2011]. Teaching is studentcentered and outcomes-based and the three main elements in an educational unit (programme, course or even for a specific intervention)—outcomes, teaching, and assessmentare aligned. This is done for the engineering masters programmes through the process of backward design, applying the understanding by design framework [Wiggens and McTiche, 2005; Wiggens and McTiche, 2011]. Backward design commences the planning process at the envisioned outcome. The next step in the planning process focuses on the assessment, or the evidence of successful learning. The last step elaborates on the teaching strategies and activities. This implies that the structure, environment, assessment and teaching strategies in a programme are created as determined by the programme outcomes. The outcomes of the engineering 


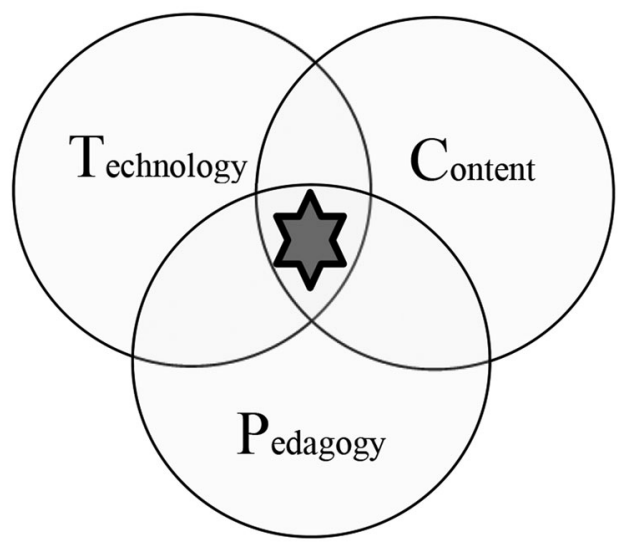

Figure 2. TCPK framework (Mishra and Koehler, 2006).

and project management masters programmes are all on the highest cognitive levels as assessed in summative examinations for each module, as well as in an integrated intermodular research project. This implies that the other aspects in the educational approach should support students' constructive processes carefully toward reaching these outcomes.

The educational approach was developed and refined over 11 years as a result of quality assurance processes and the realities of students participating in postgraduate part-time studies.

\subsubsection{Blended Teaching and Learning}

The rapid development of information and communication technology in recent years created various options to address challenges in the educational environment, especially when balanced with a focus on both the pedagogy and the content. The TPCK (technology, pedagogy, and content knowledge) framework as proposed by Mishra and Koehler [2006] is a demonstration of the importance and implementation of this balance. This framework is illustrated in Figure 2.

The three knowledge areas that describe this framework are knowledge of technology (implying knowledge of the possibilities embedded for teaching and learning within different information and communication technologies) to support appropriate pedagogy (implying knowledge of relevant teaching and learning strategies and approaches within the subject-area) when teaching the module content (implying the necessary content knowledge of the subject area). Sufficient background of these three knowledge areas creates the possibility for a lecturer to make informed decisions with regard to the teaching and learning process. Different combinations of the three aspects in the framework create different blends of teaching approaches, and the ideal would be a carefully considered combination of the three aspects, based on informed decisions - as illustrated in the centre of the Venn diagram in Figure 2.

This framework is also supported by the notion of blended learning, which can be defined from as narrow as different blends of technologies to as wide as a multimodal model, encompassing online and f-2-f, individual and collaborative teaching strategies, different learning styles, content and more [Picciano, 2009]. The blended learning framework proposed by the Clayton Christensen Institute for disruptive innovation [Christensen, 2012] defines blended learning as a "formal education program in which a student learns at least in part through online learning, with some element of student control over time, place, path, and/or pace; at least in part in a supervised brick-and-mortar location away from home; and the modalities along each student's learning path within a module or subject are connected to provide an integrated learning experience."

These discussions of blended and e-learning illustrate that the planning of learning is a holistic process, which should be approached with care and sensitivity regarding the diversity of the students and the challenges in the educational environment.

The current format of the engineering management masters programmes in the School of Technology Management developed into a blended teaching and learning approach as illustrated in Figure 1. The blended process is managed through the LMS, which provides many of the interactive and collaborative teaching and learning options necessary for successful implementation of the educational process.

\subsubsection{Learning Cycles}

The educational process is also guided by learning cycles. Learning cycles are proposed by educators as an indication of how students learn and thus how educators can design teaching to support the natural learning processes. Examples of learning cycles are the experiential learning cycle [Kolb and Kolb, 2005a,b], and the brain-based learning approach [Jensen, 2000; Jensen, 2005; Jensen, 2008]. These authors also recognize the complexity and holistic nature of the learning process. The notion of experiential learning implies that cognitive transformation is brought about by phases of "experiencing," "reflecting on the experience," "forming abstract concepts," and "applying concepts in new situations." Brainbased learning, on the other hand, originates from the application of neuroscience principles to inform educational approaches and strategies. The teaching and learning process in this case study is based on Jensen's proposal of learning as a process with different stages, and the link to physical processes within the brain. Jensen proposes that learning occurs in five stages [Jensen, 2000]. (The research in this paper focuses on the first two stages as depiction of student preparedness.)

- Preparation: this stage provides a framework for new learning and connections to previous work. It provides background and context. This stage is applied in the masters programmes as illustrated in Figure 1 in the first day of orientation (A) and also in the weeks of preparation (B) before the f-2-f block week. The aim of activities and information provided to students is to create the context of the programme and its constituent modules.

- Acquisition: this stage introduces the new concepts. The first new weak synaptic connections are formed in the brain. These connections must however be 
strengthened before learning can occur. If teaching stops at this stage, reteaching will have to take place. Strategies such as lecturing, explanation, experimentation, reading, and group work can be implemented during this stage. Acquisition is supported in the teaching and learning process in the SE module during the 4 weeks illustrated as B in Figure 1. It is expected of students to do considerable reading and online assignments during this stage, in preparation for the f-2-f sessions that will follow. Resources that are made available to the SE students include printed material, textbooks, study guides, and references to library material and websites. This stage creates the foundation for the next stage of the teaching and learning process. During the past few years, it became clear that students who were well-prepared as a result of this stage could provide meaningful contributions during the $\mathrm{f}-2-\mathrm{f}$ class time. This led to the development of a preparation test, to encourage students to prepare better and to assess their level of preparedness.

- Elaboration: this stage is a more in-depth inquiry into the topic at hand and investigations of the interconnectedness of topics. During this stage, students need to engage in the learning process explicitly (consciously through strategies such as discussions, readings, lectures, and work sheets) and implicitly (unconsciously through strategies such as real-life case studies and experiences). Feedback (marks, discussions, peer reviews, self-assessment, rubrics, and answer sheets) is of utmost importance to guide the teaching and the learning process. During this stage, weak synaptic connections in the brain are strengthened and complex neural pathways are developed that support the connection of topics in meaningful ways. The nature of modules in the engineering masters programmes, and specifically of SE (as indicated in the problem statement), emphasises the importance of this stage in the development of a practicebased approach that is a mixture of theory, heuristics, process and so-called best practice.

This stage is introduced during the 2.5 days of $\mathrm{f}-2-\mathrm{f}$ teaching ( $\mathrm{C}$ in Figure 1$)$. Since this is the only time that students and lecturers are in direct contact, the time needs to be utilized carefully and meaningfully using interactive teaching strategies. It was found that this time is counter-productive if students are not well prepared. Interactions, therefore, can only focus on the acquisitionlevel of teaching and learning, and on lower cognitive levels. The better prepared that students were, the higher the level and strategies of interaction could be during the f-2-f sessions. This also affected the students' ability to continue meaningfully with the independent work in the main study time (D in Figure 1). This created a further need for a preparation test that can motivate students and assess their meaningful participation in the acquisition phase.

- Memory formation: this stage is dependent on a variety of factors. Rest, emotions, context, nutrition, prior learning, learner state of mind and stage of development all play a role in the learning process. It takes place over time, and includes aspects such as engaging all senses, reflection on personal learning, incorporation into personal life, positive associations, peer-teaching and group work, follow-up and re-enforcement. In the SE module, this phase is supported through assignments and group work, as well as individual studies during the 14 weeks of the main study time (D in Figure 1).

- Functional integration: this stage includes extended usage. New learning is used and applied in a variety of settings. Functional integration is incorporated in the preparation for the examination; in the intermodular research project for the qualification; as well as in applications of new learning in the students' work environment.

Even though this discussion of brain-based learning is structured around definite stages, it should be stressed that the researchers understand that each student's actual learning process is unique and iterative and is not so neatly organized into stages, one following the other. These discussions focus on the structure of the teaching and learning process that informs the management of the Engineering masters programmes.

Criticism of brain-based teaching and learning is recognized and discussed by Jensen [2008], but the authors of this paper agree with his opinion that "brain-based teaching is the active engagement of practical strategies based on principles derived from brain-related sciences," and as educators we need to implement well-designed strategies in teaching. These concepts supported the development of the engineering masters programmes well over the past years. The importance of active engagement and interactive teaching strategies utilized in the f-2-f sessions of the masters programmes and the SE module specifically are discussed next.

\subsubsection{Interactive Teaching Strategies}

The teaching approaches during f-2-f sessions (D in Figure 1) differ considerably between presenters. The relatively short contact time (only 2.5 days per module per semester), necessitates that programme coordinators encourage interactive teaching strategies. The teaching blocks are typically organized with interactive teaching sessions, group activities, individual and collaborative assignments, class discussions and presentations, and interactive lectures. These approaches support the notion of higher level interaction necessary for the elaboration phase in the brain-based learning approach.

A variety of $\mathrm{f}-2-\mathrm{f}$ teaching strategies that promote higher level engagement are described by educators. These include, among others, active learning (AL) [Felder and Brent, 2003, 2009; Prince, 2004], peer instruction (PI) and justin-time-teaching (JiTT) [Crouch and Mazur, 2001; Fagen, Crouch, and Mazur, 2002], and the flipped-classroom [Herman, 2013] approaches. Some of the strategies employed for the engineering masters programmes are adaptations of $\mathrm{AL}$ [Prince and Felder, 2006; Felder and Brent, 2009], PI and JiTT [Mazur and Watson, 2010], and the flipped classroom [Herman, 2013]. At the core of all these strategies is the importance of the students' high-level engagement with the work. The success of these interactions was found to be directly dependent on students' preparedness as a result of the acquisition phase. 
The AL strategy is implemented in the f-2-f sessions (C), which are typically structured in shorter units of lecturing, and brief but challenging interactive sessions during which students engage with the work either as individuals or as small groups (implementing elements of PI). The quality of the interactive sessions is dependent on students' preparedness. It is also essential that lecturers are trained and motivated to be able to effectively facilitate these interactive learning sessions.

The notion of a flipped classroom also links to active learning and JiTT, as this concept is based on the importance of students' preparation of work on the lower levels of the learning taxonomies before the f- 2 -f class, to ensure that precious class time can be utilized to work on the higher cognitive levels, instead of the lecturer-centered teaching of these concepts.

This brings the discussion to JiTT, which implies that students have to prepare for class (through readings, assignments, and videos) and communicate with the lecturer before the f-2-f session about the challenges they encounter during this preparation. This corresponds to the acquisition phase in brain-based learning (B in Figure 2). Students' preparedness in JiTT is traditionally assessed through an online test, as well as through messages to the lecturer (through blogs and discussion boards, for example), all of which contribute to the blended nature of a course [Paterson, 2005]. The lecturer uses this information to inform the focus of and activities in the $\mathrm{f}-2$-f sessions.

This idea is applied in the SE module in a preparation test, currently written at the beginning of the f-2-f teaching block ( $\mathrm{C}$ in Figure 1), after students have worked through prescribed readings, assignments and other material during the preparation and acquisition phases (B in Figure 1). The preparation test concept was adapted for application in postgraduate studies and is discussed in detail later.

\subsubsection{Levels of Learning}

Benjamin Bloom designed one of the first learning taxonomies in 1956 in an attempt to promote higher levels of mental interaction for teaching and learning [Bloom, 1956; Clarke, 1999]. The original taxonomy proposed three domains of educational objectives, namely cognitive, affective, and psychomotor. The affective domain is formalized in specific modules and also addressed in a personal development programme in the engineering and project management masters programmes. The cognitive domain was explored further in this research due to the focus on the first two phases of the learning process. The original cognitive levels in the taxonomy were knowledge, comprehension, application, analysis, synthesis, and evaluation.

The revised and expanded version of the cognitive domain, as presented by Krathwohl was found to be a meaningful guide in planning for appropriate teaching and assessment in the engineering management programmes [Krathwohl, 2002]. Krathwohl proposed that the cognitive domain of Bloom's taxonomy should be presented in two dimensions, namely a cognitive process dimension (the revised Bloom's taxonomy levels), and a knowledge dimension. This was adapted and is illustrated in Figure 3.
The knowledge dimension was derived from the need to represent the type of subject matter content that is involved (a noun phrase) in conjunction with the cognitive learning processes (a verb phrase). This corresponds to representations of a learning outcome in terms of a noun phrase and a verb phrase.

This taxonomy revised the original cognitive levels into the proposed cognitive learning process levels (verbs) of remember, understand, apply, analyze, evaluate, and create. The four highest levels are emphasized in the outcomes of the two masters programmes and are assessed in summative assessments (examination and intermodular project). The proposed highest level, create, corresponds to the high level of responsibility in the workplace, where these students are typically employers and expected to be on the forefront of managing and inspiring innovation. It is, however, a challenge to promote higher levels of thinking within the blended structure of these programmes, especially in the light of the short f-2-f teaching time. The value of the preparation and acquisition phases in the brain-based learning model became more and more apparent, in this regard, during the years of refining the structure of these programmes. If students are well-prepared on the remember and understand levels, and introduced to the apply level of the taxonomy, the activities in the f-2-f sessions can be pitched at the higher levels. This in turn could positively affect the levels of students' engagement with their work during the main study time.

On a side-note: It is interesting to observe that the higher cognitive levels defined by both Bloom and Krathwohl correspond with the three fundamental SE activities, that is, analyze, evaluate, and synthesize. Synthesize in this context means "putting things (components or entities) together, hence creating something of value" [Eisner, 2008; Blanchard and Fabrycky, 2010]. This reemphasizes the notion that the design of a teaching and learning environment or an educational process (system) is in fact an application of a SE process at its core.

The knowledge dimension proposed by Krathwohl consists of the following categories of subject matter content:

- Factual knowledge describes the basic knowledge that underpins a discipline.

- Conceptual knowledge refers to the interrelationships amongst the basic concepts.

- Procedural knowledge focuses on methods, processes, criteria used and techniques to do something.

- Meta-cognitive knowledge indicates awareness and knowledge of one's own cognition.

Krathwohl [2002].

This two-dimensional representation creates the possibility of investigating different cognitive aspects of teaching and learning within Bloom's taxonomy. In the context of this paper, the preparation test was evaluated through well-thoughtthrough placements of the test-items on the intersections of the dimensions. The following example illustrates this. 


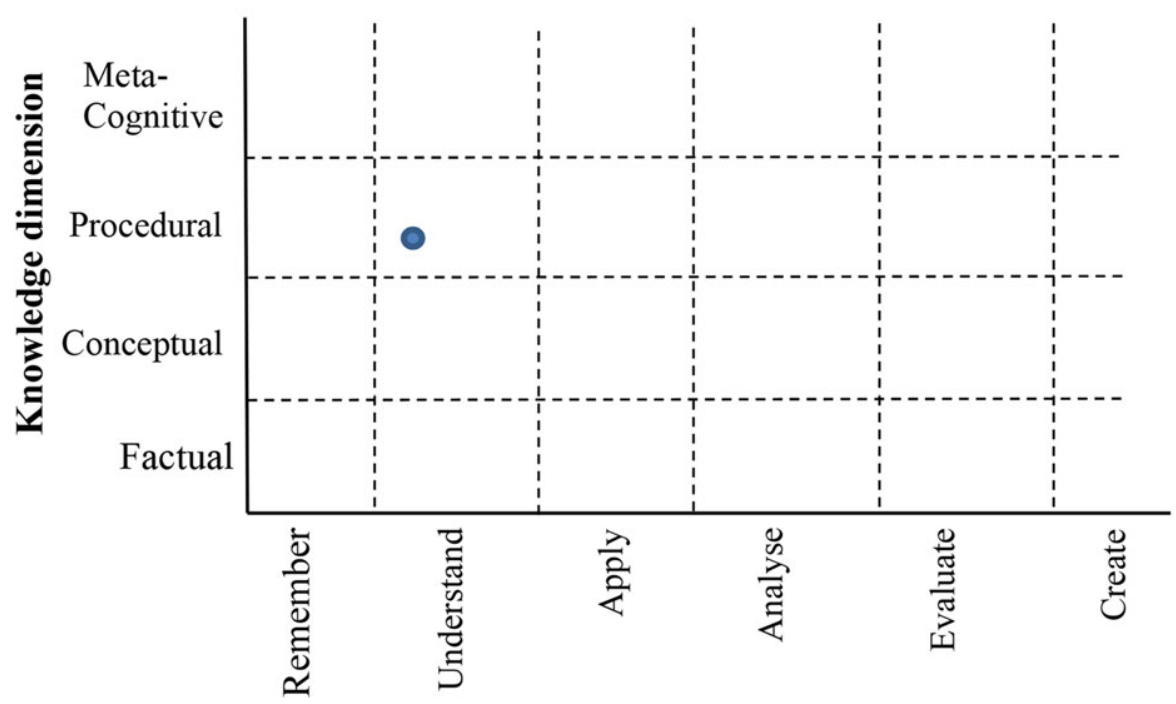

\section{Cognitive process dimension}

Figure 3. Two-dimensional representation of Bloom's taxonomy (Adapted from Krathwohl, 2002).

\section{Example question}

What are the advantages of the "interactive, iterative, and integrative" process of system or product development? Select the one most suitable answer.

(a) The development process is easier to manage.

(b) Technical risk can easily be addressed during the manufacturing and operational phases because of this method of working.

(c) This process ensures that design requirements, for example, functionality, cost, manufacturability and supportability are early and simultaneously played off against each other, thereby ensuring an optimum design.

(d) Easier to use Computer Aided Systems Engineering Systems ("CASE") tools to improve the utilization of scarce technical manpower during the total life cycle of the system.

(e) Reliability and maintainability can be addressed early in the operational phase of the system and hence save time and money.

\section{Discussion}

This question originates from a description of the SE process in literature [Blanchard and Fabrycky, 2010; INCOSE, 2011]. The question is depicted in Figure 3 in the area where the procedural (knowledge dimension) and the understand (cognitive process dimension) intersect. The test is a closedbook test based on the reading material provided for the acquisition phase (B) in Figure 1. The advantages indicated in the example question are not explicitly listed in the reading material and students thus have to derive it-placing it on the understand level in the cognitive process dimension. The type of knowledge involved here requires insight of an involved process ("interactive, iterative, and integrative"); hence it is placed on the procedural level. All the preparation test questions (items) were similarly carefully considered before allocated to a specific area, as illustrated in Figure 4.

\subsubsection{Summary: Teaching and Learning Process}

Table I summarizes the teaching and learning process for the engineering management programmes and specifically the SE modules. The first column indicates the module lifecycle phases and the position of the preparation test within this life cycle, as illustrated in Figure 1. The intermodular research project is also depicted in this table, as it links to the important functional integration phase in the brain-based learning approach. Different aspects of blended learning are indicated in the second column, focusing on online/distance and f-2-f sessions. The third column illustrates how the different phases of the brain-based learning are structured within the module. The preparation test is utilized to assess students preparedness after the acquisition phase, and to inform the teaching and learning for the elaboration and memory formation phases. The main teaching strategies are depicted in the fourth column. The fifth column illustrates how mainly the first two levels of the adapted Bloom's taxonomy are addressed before the preparation test, as well as the level of the preparation test (mainly remember, understand, and to some extent apply), to ensure that teaching and learning in ensuing phases and in the summative assessments can be pitched towards the higher levels. The last column summarizes the duration of each of the phases in the module life cycle.

This concludes the discussion of research subquestion 1: how can masters in engineering and project management programmes be structured to support student preparedness?

The next paragraph discusses the SE preparation test in more detail, and focuses on research subquestion 2: how can a preparation test be implemented to support student preparedness? 


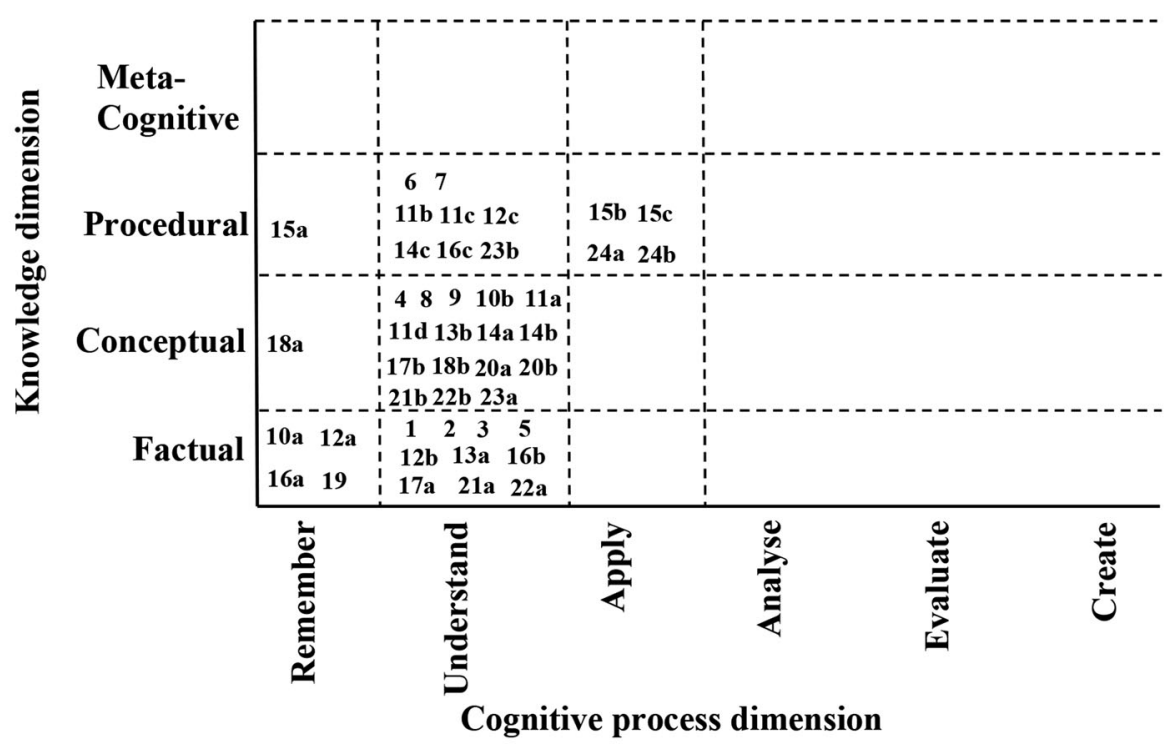

Figure 4. Preparation test educational analyses.

Table I. Teaching and Learning Process Summary

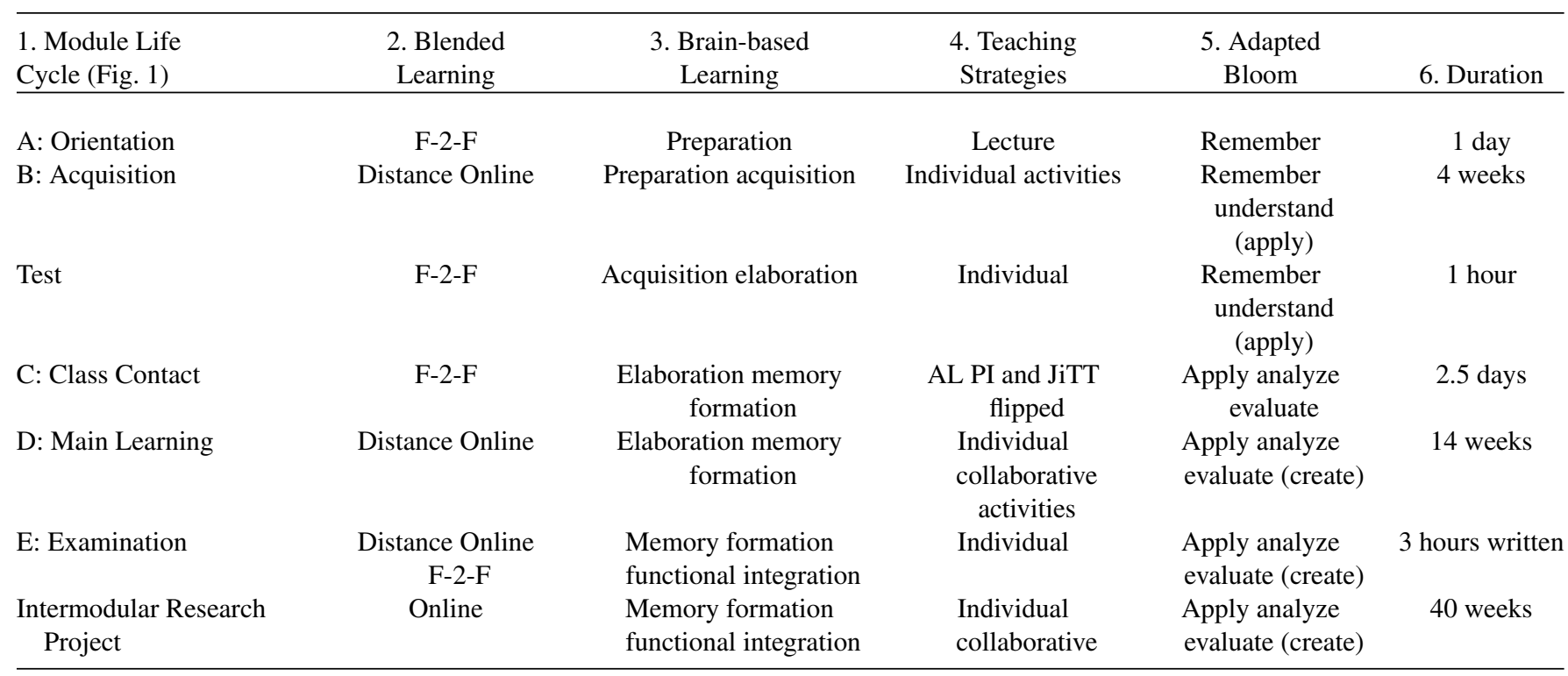

\section{SE PREPARATION TEST}

The SE preparation test was designed to assess students' preparedness of the reading material and assignments during the acquisition phase in the teaching and learning process. The test idea originates from the typical pre-tests discussed in JiTT and PI as well as the flipped classroom teaching approaches. The purpose, however, differ from the typical undergraduate applications, in that it is also aimed at higher cognitive levels as appropriate for postgraduate studies. Other differences are discussed here. The purpose of the activities in the acquisition phase is to highlight typical mistakes in the engineering management field, and also to help students to recognize and understand these, hence developing their systems awareness. How these mistakes should be approached and solved is subsequently discussed in the f-2$\mathrm{f}$ class and addressed in other phases of the teaching and learning process. The test is currently written as a closed-book test at the beginning of the $\mathrm{f}-2-\mathrm{f}$ session ( $\mathrm{C}$ in Figure 1$)$. It is immediately evaluated and the results are made available to the lecturer and students.

\subsection{Origin and Rationale}

The content studied in the acquisition phase, as well as the items in the SE preparation test, originated from the 
researchers' experience participating in and managing reallife projects in industry. It was observed in different companies and on a variety of projects that people make and repeat typical mistakes. Most of the mistakes can probably be traced back to a lack of system-oriented planning and execution. Often system/product designers are young, inexperienced people. They do not fully understand the SE process, do not see the bigger system picture, are overwhelmed by detail and often lose sight of the key requirements. Systems are often developed focusing only on part of a system, not the total system. Designers often focus on required functional performance, downplaying issues such as manufacturability, supportability, and life-cycle cost. In an effort to cut development cost, important longer term challenges are overlooked or simply ignored.

Engineers also tend to focus on the solution, without a thorough understanding of the problem. Often problems and system requirements are not properly identified, analyzed, defined, or documented. A focused and traceable requirement management process is not executed. Engineers furthermore tend to focus on physical issues, not on human or information issues. Project managers, system engineers, and designers are often measured on short-term milestones, ignoring the longer term (life-cycle perspective). Short-term return on investment is emphasized, which results in the creation of rushed halfbaked designs and putting these into production.

The knowledge and information era has brought along exciting (technological) capabilities, but also huge complexities. Over and above the technical challenges of any project, the information challenge must also be addressed.

The above-mentioned mistakes often occur across organizational boundaries, indicating a lack of organizational integration. Project management, SE and business process management are often inadequate.

The SE preparation test is designed to assess student's understanding of the general background of the field, basic terminology and theory of SE, as well as their insight into the challenges in the field as discussed.

\subsection{Evolution of the Preparation Test over Time}

The following discussions focus on the question: how can the preparation test motivate students to prepare more effectively toward meaningful $f-2-f$ interaction?

Different formats of the preparation test have been used over the years, although the type of questions and the content remained similar. The different formats are: paper-based in class; online in laboratories on campus (supervised); online on the LMS via internet (unsupervised); and slides in class. The number of questions was significantly expanded over time, specifically to allow for meaningful and fair online tests, randomly selecting similar questions from question sets to create a unique test for each student. Care was taken to group similar questions into categories to allow for meaningful random selection. These different formats are being investigated to try to find any trends in marks achieved. Currently, a slide show in class showing questions on a data projector is used. Students answer on optical mark sheets which are processed directly after each test. Marks are therefore quickly available. It is interesting to note that students prefer paperbased tests in class which they experience as "less confusing" than computer-based tests.

\subsection{Educational Analysis}

The educational analysis of the preparation test focuses on the impact of the test on the teaching and learning process, as well as an analysis of the individual test items and the test as a whole.

\subsubsection{The Impact of the Test on the Teaching and Learning Process}

The following discussion focuses on the question: how can the results of the preparation test contribute to in-process adaptation of teaching and learning activities in the SE module?

The preparation test is placed within the teaching and learning process, as indicated in Figure 1 and summarized in Table I, at the beginning of the $\mathrm{f}-2-\mathrm{f}$ session.

In the brain-based approach, the preparation test is formally at the end of the acquisition phase and at the beginning of the elaboration phase-giving it a dual purpose. First, the preparation test assesses students' involvement in the acquisition stage, and, second, it informs the teaching and the learning for the elaboration stage (and further). The test was found to be a motivator for students to engage in the preparation and acquisition stages of the teaching and learning process, as there was a marked improvement in students' level of preparedness when the test was instituted. This was evident in the higher level of discussions during f-2-f sessions. The statistical analysis of the test results, as discussed later, also indicates the impact of the level of students' preparedness on the remainder of the phases as well as on their eventual success in the module.

Second, the results also inform the lecturer's teaching approach and supports interactive strategies such as AL, PI and JiTT, on higher cognitive levels, as discussed before. Last, the test is designed to assess students' level of preparedness and their technical and conceptual approach to the work on the lower levels of both dimensions in Bloom's taxonomy (Figure 3). This is illustrated in Figure 4 and discussed in detail in the next section. Students as well as lecturers have immediate access to the test results, and therefore these results can inform the lecturer of possible lower cognitive and knowledge level issues, which firstly can be addressed in the $\mathrm{f}-2$-f session. Thereafter interactions can focus on the higher cognitive levels of Bloom's taxonomy.

\subsubsection{Analysis of the Test-Items and the Test as a Whole}

The following discussion focuses on the question: are the SE items in the preparation test posed at appropriate cognitive levels given the stage of learning?

Each item in a typical test was analyzed as illustrated in Figure 3, and plotted in Figure 4. Single questions are numbered Q1, Q2, etc., and sets of related questions are numbered $\mathrm{Q} 3 \mathrm{a}, \mathrm{Q} 3 \mathrm{~b}$, etc. Decisions of where to plot a question were 
guided by whether or not the knowledge assessed is on a factual, conceptual or procedural level (on the vertical axis), as well as the cognitive processes that can be expected to be involved at this stage of the learning process.

It is clear from Figure 4 that the focus of the preparation test is on the cognitive process dimension levels of remember, understand, and the apply level. The knowledge dimension focuses on factual, conceptual as well as procedural knowledge. Factors that influenced decisions regarding the placement of questions were, apart from the indicators on the two axes, also whether or not the information needed to answer the question was provided directly within the reading and other material, or whether or not a student needed to derive the answer from the provided information and/or own experience. This distribution of questions indicates that the test items are at the appropriate level for postgraduate studies and for the specific purpose of the test in this subject as discussed earlier.

Also note how related questions are typically developing in complexity, for example, Question 12a on factual/remember, $12 \mathrm{~b}$ on factual/understand, and $12 \mathrm{c}$ on procedural/understand levels. The set of questions, therefore, is in itself a learning experience and guides the students towards higher level interaction with the content.

\subsection{Statistical Analysis of Test Results}

The following discussion focuses on the question: can the results of the preparation test be considered as a meaningful predictor of course success?

Preparation test and final examination results of 11 years were analyzed and interesting findings were made. However, the aim of the statistical analysis presented here is to identify overall trends, and to address the specific research question: can the results of the preparation test be considered as a meaningful predictor of course success? The aim was not a detailed analysis and attempt to identify, analyze, and explain (small) differences between different test results in various SE modules.

When analyzing preparation test results over years, it became clear which parts of introductory material students did not master. This enabled the lecturer immediately to adapt the teaching and learning strategy during f-2-f sessions and the subsequent main learning stage. This JiTT adaptation proved to be valuable to students and significantly enrich their learning experience. It was furthermore evident that students who performed badly in the preparation test (set at lower cognitive levels) also experienced problems in mastering the remainder of the study material and consequently battled to excel in the final examination (set at the highest cognitive levels). The opposite was apparently also true.

The results of the SE module of the engineering management programme are depicted in Figure 5, that is, 503 data sets were recorded. The SE module results of the project management programme are depicted in Figure 6, showing 517 data sets. Preparation test and exam marks are plotted as paired sets in both figures using Excel.

The correlation in Figures 5 and 6, respectively, is 0.462 and 0.474 , which is a moderate correlation. A variety of external factors could influence test and examination results, for example, personal reasons, work-related problems, logistic problems of students, or simply at lack of study. The tests and examinations were also adapted over the years and kept similar but not identical. This could also explain differences or outliers. There are a number of outliers that could probably be investigated and explained. However, this was not the intention. If the most prominent outliers could be explained and then ignored, then the correlation would also be considerably stronger. Hence, the data is considered to be reliable and valid, taking into account that the study was done over 11 years as well as the fact that a variety of external factors cannot be controlled.

Cross tabulation and chi-square tests were subsequently done using SPSS as shown in Tables II and III for the two respective programmes. Test and examination marks were structured into groups 1.00 (1-10), 2.00 (11-20), 3.00 (2130), 4.00 (31-40), etc.

The chi-square tests also confirm a moderate relationship among test and examination results. Both correlation tests and chi-square tests confirm that the preparation test result can be used as a meaningful prediction of course success. However, more in-depth statistical analyses will be required to understand fully the relationship between preparation test and examination data.

The research questions are discussed and findings explained in the subsequent paragraphs.

\section{DISCUSSION OF FINDINGS}

This section focuses on the discussions of the main research question: how can students' effective preparations, as assessed in a preparation test, positively influence teaching and learning activities in a SE module?

Subresearch question 1: how can masters in engineering and project management programmes be structured to support student preparedness?

The longitudinal case study described in this paper, resulted in a formal and formalized description of an educational process that was designed to address the challenges in postgraduate engineering management education. The underlying value of student preparedness was built into this process through application of constructive alignment and learning cycles as managed through an interactive blended teaching and learning approach. The educational process is summarized in Figure 1 and Table I, with specific focus on preparation within this process.

Subresearch question 2: how can a preparation test be implemented to support student preparedness?

This question was investigated on the hand of four questions. Summaries of findings are provided here.

(a) How can the preparation test motivate students to prepare more effectively towards meaningful f-2-f interaction?

The simple fact that students know that a preparation test is going to be written on the first day of class contact signifies that the lecturer is serious about the 
Preparation test vs. Exam marks

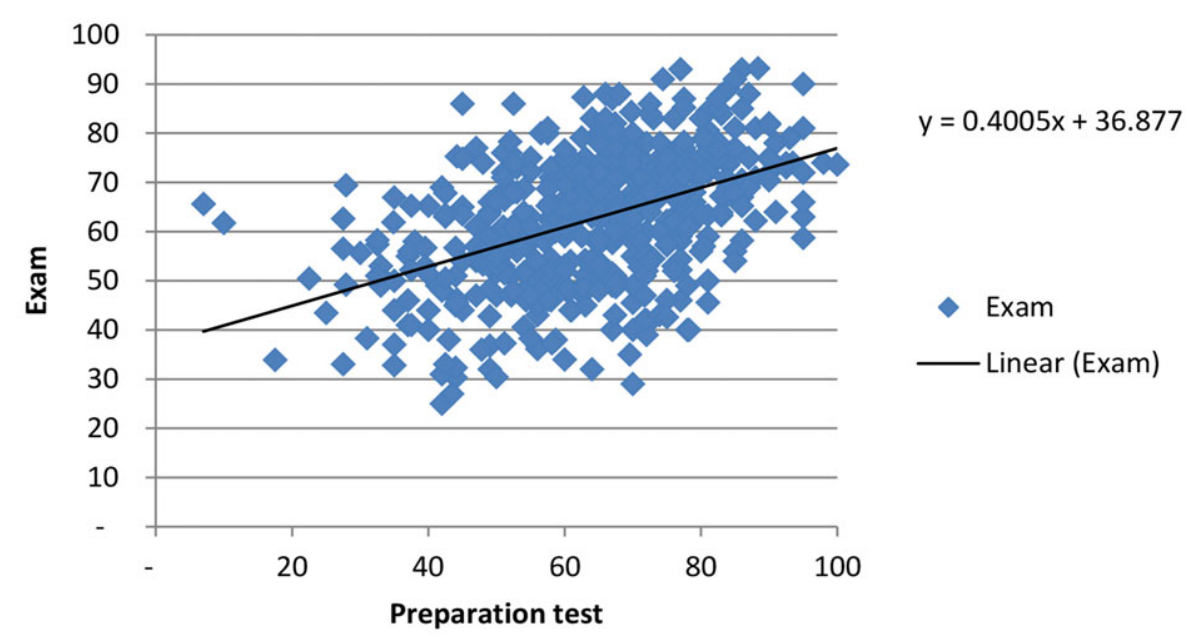

Figure 5. Preparation test and Exam results (Engineering Management SE module).

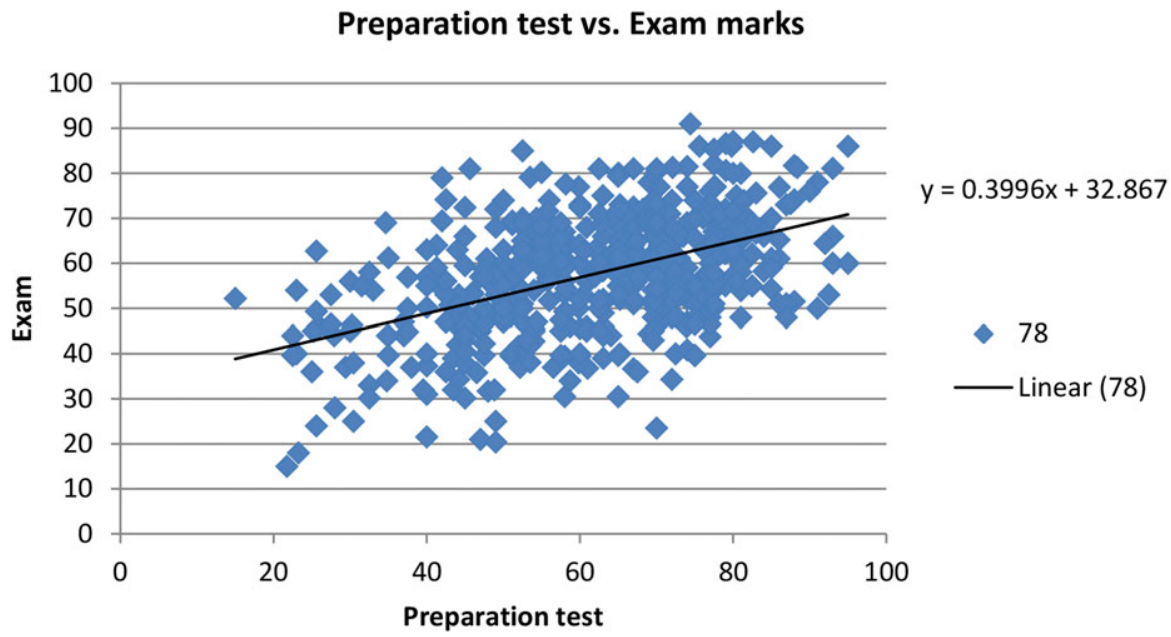

Figure 6. Preparation test and Exam results (Project Management SE module).

course and specifically thorough preparation. Since the inception of this test, notably more students tend to take more care with reading the study guide and prescribed prereading material and doing the assignments. Furthermore, they search and find specific reference documents in electronic library environments and on the internet. They also enthusiastically experiment with the LMS in order to find study material and master the basic functionalities. All activities aim to support students' preparedness for f-2-f session and are assessed in the preparation test.

(b) Are the SE items in the preparation test posed at appropriate cognitive levels given the stage of learning? The focus of the preparation and acquisition phase in the educational process is on providing a framework for learning and connections to new work, as well as introduction to new facts, concepts and procedures. The analysis of the preparation test, as depicted in Figure 4, confirms that the test is focused on the appropriate cognitive and knowledge levels. Most items are plotted on the cognitive process dimension, ranging from remember to apply and on the knowledge dimension from factual, conceptual to procedural. These plots indicate a meaningful and appropriate preparation and acquisition process. It is very clear that students should master these introductory items before f-2-f sessions, to enable them to participate effectively on higher cognitive levels.

(c) How can the results of the preparation test contribute to in-process adaptation of teaching and learning activities in the SE modules?

The teaching and learning process is illustrated in Figure 1 and Table I. The pivotal position of the preparation test is illustrated in both. This allows for adaptation of the educational process early in the programme. The adaptation of the educational process is two-fold, namely, adaptation of teaching and adaptation of learning. The lecturer has direct access to the test results and 
Table II. Test and Exam Cross Tabulation (Engineering Management SE Module)

\section{Exam}

$\begin{array}{lllllllll}3.00 & 4.00 & 5.00 & 6.00 & 7.00 & 8.00 & 9.00 & 10.00 & \text { Total }\end{array}$

\begin{tabular}{lcccccccccc}
\hline Test & 1.00 & 0 & 0 & 0 & 0 & 2 & 0 & 0 & 0 & 2 \\
& 2.00 & 0 & 1 & 0 & 0 & 0 & 0 & 0 & 0 & 1 \\
& 3.00 & 0 & 1 & 2 & 2 & 2 & 0 & 0 & 0 & 7 \\
& 4.00 & 0 & 4 & 7 & 12 & 4 & 0 & 0 & 0 & 27 \\
& 5.00 & 2 & 7 & 11 & 17 & 14 & 4 & 1 & 0 & 56 \\
& 6.00 & 0 & 7 & 13 & 23 & 23 & 17 & 2 & 0 & 85 \\
& 7.00 & 1 & 4 & 15 & 25 & 35 & 31 & 8 & 0 & 119 \\
& 8.00 & 0 & 3 & 9 & 22 & 34 & 32 & 7 & 2 & 109 \\
& 9.00 & 0 & 0 & 2 & 4 & 11 & 20 & 12 & 3 & 52 \\
& 10.00 & 0 & 0 & 0 & 1 & 3 & 9 & 2 & 0 & 15 \\
Total & & 3 & 27 & 59 & 106 & 128 & 113 & 32 & 5 & 473 \\
\hline
\end{tabular}

Chi-square test (engineering management SE module)

Asymp. Sig.

\begin{tabular}{lccc} 
& Value & df & (2-sided) \\
\hline Pearson Chi-Square & $154.713^{\mathrm{a}}$ & 63 & .000 \\
Likelihood Ratio & 146.744 & 63 & .000 \\
Linear-by-Linear Association & 89.527 & 1 & .000 \\
Number of Valid Cases & 473 & & \\
\hline
\end{tabular}

Table III. Test and Exam Cross-Tabulation (Project Management SE Module)

\section{Exam}

2.003 .004 .005 .006 .007 .008 .009 .0010 .00 Total

\begin{tabular}{cccccccccccc}
\hline Test & 2.00 & 0 & 0 & 0 & 0 & 1 & 0 & 0 & 0 & 0 & 1 \\
& 3.00 & 2 & 2 & 4 & 7 & 3 & 1 & 0 & 0 & 0 & 19 \\
& 4.00 & 0 & 1 & 8 & 6 & 7 & 3 & 0 & 0 & 0 & 25 \\
& 5.00 & 0 & 2 & 9 & 22 & 23 & 7 & 5 & 1 & 0 & 69 \\
& 6.00 & 0 & 0 & 11 & 21 & 30 & 30 & 8 & 1 & 0 & 101 \\
& 7.00 & 0 & 1 & 6 & 11 & 38 & 41 & 18 & 3 & 0 & 118 \\
& 8.00 & 0 & 0 & 5 & 14 & 27 & 35 & 15 & 8 & 1 & 105 \\
& 9.00 & 0 & 0 & 0 & 2 & 10 & 13 & 8 & 4 & 0 & 37 \\
& 10.00 & 0 & 0 & 0 & 1 & 3 & 2 & 2 & 2 & 0 & 10 \\
\multicolumn{1}{l}{ Total } & & 2 & 6 & 43 & 84 & 142 & 132 & 56 & 19 & 1 & 485 \\
\hline
\end{tabular}

Chi-Square Test (Project Management SE Module)

Asymp. Sig.

\begin{tabular}{lccc} 
& Value & df & (2-sided) \\
\hline Pearson Chi-Square & $179.638^{\mathrm{a}}$ & 64 & .000 \\
Likelihood Ratio & 140.418 & 64 & .000 \\
Linear-by-Linear Association & 92.946 & 1 & .000 \\
Number of Valid Cases & 485 & & \\
\hline
\end{tabular}

can investigate totals and averages, individual students' marks, as well as individual question results. This information allows for JiTT adaptation as it allows the lecturer to focus primarily on specific problem areas, adapt subsequent lectures, and select the most appropriate student class presentations and group activities to enhance the learning. This approach also provides insight in terms of the selection of meaningful group assignments for the subsequent main study period. The lecturer uses the opportunity to interact with students who performed exceptionally poorly in order to encourage them and provide them with guidance on how to approach and plan their study programme better and adapt their work methods.

From a learning perspective, students feel more empowered and experience a more interactive learning journey. They also feel that their individual needs are catered for. This is important in larger groups. Students know which knowledge areas they did not master and can ask meaningful questions. This considerably raises their confidence to participate in class discussions and subsequent group assignments.

(d) Can the results of the preparation test be considered as a meaningful predictor of course success?

The statistical data analysis confirmed a relation between the results of the preparation test and the final examination, albeit not very strongly. The test results proved to be valuable for the lecturer to obtain an early indication of the performance of individual students and overall class performance as discussed above. Students who performed unsatisfactorily in the preparation test can be identified early and a serious effort can thus be made to encourage and help them to refocus their study. The data in Figures 5 and 6 also provides important insights. When analyzing preparation test data, one can see that the engineering management groups perform slightly better than the project management groups on average. The engineering management groups also do better in the top end of the preparation test (one even obtaining 100\%). This can be explained in terms of the type of job the students do and their specific interest in SE. A typical problem with the final examination is that students struggle to complete it in time and very seldom obtain marks above $90 \%$. The examination is obviously pitched on the higher cognitive and knowledge levels, and it also assesses all the work of the semester, after students have worked through the other phases of the education process.

\section{CONCLUSION AND RECOMMENDATIONS}

The first outcome of this investigation is the description of a structured teaching and learning process as applied in the engineering and project management masters programmes, and specifically in the SE module, as developed over a period of time. Relevant pedagogical theories could be identified and used to analyze and clarify the actual learning process and the importance of the acquisition stage within a blended teaching and learning environment. The preparation test proved to be meaningful and presented at appropriate cognitive levels in terms of items posed. The preparation test indeed makes JiTT adaptation of the teaching and learning process feasible. The preparation test can furthermore act as a predictor of course success as shown by the data analysis. It is, however, not meant to be used as an accurate 
predictor, but rather an early indicator to enhance adaptation of teaching and learning. The overriding message signifies the importance of the preparation and acquisition stages in an interactive blended teaching and learning approach. Careful, holistic, and thorough planning is of the utmost importance to achieve this. It must be furthermore measured and updated continuously.

A more in-depth analysis and clarification of the preparation test data is proposed to be part of further research. A variety of analyses are possible to make better use of the available data. One early indication is that the graphs in Figures 5 and 6 can be better explained using more advanced analysis techniques. Further analysis is also being planned to acquire insight into specific examination questions and results. These data can be fed back to improve f-2-f sessions in the future. The examination paper also evolved over time. New questions were added, in relevant categories in terms of stages/topics of the SE process and cognitive level. Research regarding the improvement of the early stages of learning and its implementation on other related courses is also envisaged. This should have a positive influence on through-put rates in the engineering management masters programmes.

This research emphasizes the importance of a well-planned educational approach and presents an educational process for postgraduate programmes. The importance of the preparation and acquisition phases within this process is furthermore established, to ensure student preparedness for teaching and learning toward higher cognitive outcomes.

The utilization of the SE approach in the investigations in this paper supported the process towards creating a wholesystem solution in the complex and diverse environment of SE education.

\section{REFERENCES}

M.E. Auer, D. Dobrovska, and E. Arthur, New pedagogic challenges in engineering education and the Answer of IGIP. Paper presented at the 41st ASEE/IEEE Frontiers in Education Conference, Rapid City, SD, 2012.

J. Biggs, and C. Tang, Teaching for quality learning at university. McGraw-Hill, Maidenhead, 2011.

B.S. Blanchard, System engineering management, 4th edition, Wiley \& Sons Inc, Hoboken, NY, 2008.

B.S. Blanchard, and W.J. Fabrycky, Systems engineering and analysis, 5th edition, Prentice Hall, Upper Saddle River, NY, 2010.

B.S. Bloom, Taxonomy of educational Objectives, handbook I: The cognitive domain, David McKay Co Inc, New York, 1956.

J. Case, 2006. Issues facing engineering education in South Africa. Paper presented at the Proceedings of the 3rd African regional conference on engineering education, Pretoria. Conference Paper retrieved from 7 November 2014, http://www.aeea.co.za/ i/i//ARCEE3.pdf

C. Christensen, 2012. Blended Learning. Retrieved 20 September, 2013, from http://www.christenseninstitute.org/blendedlearning-3/
D. Clarke, 1999. Bloom's Taxonomy of Learning Domains. Retrieved 19 September, 2013, from http://www.nwlink. com/ donclark/hrd/bloom.html

J.W. Creswel, Qualitative inquiry and research design: Choosing among five approaches, 3rd edition, SAGE, Thousand Oaks, 2013.

C.H. Crouch and E. Mazur, Peer Instruction: Ten years of experience and results, Am J Phys 69(9) (2001), 970-977.

H. Eisner, Essentials of project and systems engineering management, 3rd editon, Wiley \& Sons, New York, 2008.

A.P. Fagen, C.H. Crouch, and E. Mazur, Peer instruction: Results from a range of classrooms, Phys Teacher 40 (2002), 206209.

R.M. Felder, and R. Brent, Learning by doing. Chem Eng Edu 37(4) (2003), 282-283.

R.M. Felder and R. Brent, Active learning: An introduction, ASQ Higher Education Brief 2(4) 2009, Online article, accessed 7 November 2014.

O. Franks, ECSA strategic plan 2010-2014. ECSA, Johannesburg, 2011.

R.L. Herman, Letter from the editor-in-chief: The Sage on The Stage, J Effect Teach 12(3) 2013, 1-4.

INCOSE. Systems engineering handbook: A guide for system life cycle processes and activities. International Council on Systems Engineering, San Diego, 2011.

E. Jensen, Brain-based learning: The new science of teaching and training. Corwin Press, Thousand Oaks, 2000.

E. Jensen, Teaching with the brain in mind, 2nd edition, Association for Supervision and Curriculum Development, Alexandria, VA, 2005.

E. Jensen, A fresh look at brain-based education, Phi Delta Kappan Magazine 89(6) (2008), 408-417.

A.A. Kolb and D.A. Kolb, The Kolb learning style inventoryVersion 3.1 technical specifications. Hay Resources Direct, Boston, MA, 2005a.

D.A. Kolb and A.A. Kolb, Learning styles and learning spaces: Enhancing experiential learning in higher education, Acad Manage Learn Edu 4(2) (2005b), 193-121.

Krathwohl. A revision of Bloom's taxonomy an overview, Theor Pract 41(4) (2002), 212-264.

M. Maier and E. Rechtin, The art of systems architecting, 3rd edition, CRC Press, Boca Raton, 2009.

E. Mazur and J. Watson, Just-in-time teaching and peer instruction, in S. Simkins and M. Maier (Editors), Just in time teaching: Across the disciplines, across the academy, Stylus Publisher, Virginia, 2010, pp. 39-62.

P. Mishra and M.J. Koehler, Technological pedagogical content knowledge: A new framework for teacher knowledge, Teachers Coll Record 108(6) (2006), 1017-1054.

E.T. Paterson, Just-in-time teaching: Technology transforming learning: A status report, Invention and Impact: Building Excellence in Undergraduate STEM (Science, Technology, Engineering, and Mathematics) Education. American Association for the Advancement of Science, Washington, 2005.

A.G. Picciano, Blending With purpose: The multimodal model, J Res Center Edu Technol 13(1) (2009), 7-18. 
M.J. Prince, Does active learning work: A review of the research. J Eng Edu 93(3) (2004), 223-231.

M.J. Prince and R.M. Felder, Inductive teaching and learning methods: Definitions, comparisons, and research bases, J Eng Edu 95(2) (2006), 123-138.

A. Pyster, D.H. Olwell, T.L.J. Ferris, N. Hutchison, S. Enck, J. Anthony, D. Henry, and A. Squires, (eds.). Graduate reference curriculum for systems engineering $\left(\mathrm{GRCSE}^{\mathrm{TM}}\right)$. Trustees of the Stevens Institute of Technology, Hoboken, NY, 2012.
R. Stephens, Aligning engineering education and experience to meet the needs of industry and society, Bridge: Undergrad Eng Edu 43(2) (2013), 31-34.

G.P. Wiggens, and J. McTighe, The understanding by design guide to creating high-quality units. ASCD, Alexandria, 2011.

G.P. Wiggens, and J. McTighe, Understanding by design. ASCD, Alexandria, 2005.

R. Yin, K. Case study research: Design and methods, 5th edition, SAGE, Thousand Oaks, 2013. 